\title{
STUDY OF ANATOMICAL VARIATIONS (DIVISION) OF MEDIAN NERVE IN CARPAL TUNNEL IN NORTH GUJARAT
}

Pankaj B Maheria ${ }^{1}$, Kuldeep N Suthar *2.

${ }^{1}$ Associate Professor, Department of Anatomy, GMERS Medical College, Dharpur-Patan, India.

${ }^{* 2}$ Assistant professor, Department of Anatomy, GMERS Medical College, Dharpur-Patan, India.

\section{ABSTRACT}

Introduction: Carpal Tunnel Syndrome is very common peripheral neuropathy in the wrist due to compression of Median Nerve. Detail knowledge of the normal and variant anatomy of the median nerve in the wrist is fundamental for clinical examination and also in avoiding complications during carpal tunnel surgeries.

Materials and Methods: A study of the variations of the course of the median nerve within the carpal tunnel were carried out on 60 wrists from 30 formalin fixed adult human cadaver for a period of 3 years in the Department of Anatomy.

Result: We found variations in 40 [66\%] hands out of 60 [100\%]. In left hand variations were more compared to right. Rare variations were not found. High division was found in 6 [10\%] of all the hands. Among them, 4 were in left hand and 2 were in right hand.

Conclusion: Sometimes incomplete decompression by surgeon for nerve entrapment and injury to its thenar branches may happen. Sound knowledge about the normal anatomy of the median nerve has become absolutely necessary to avoid such incidences.

KEY WORDS: Median nerve, Carpal tunnel, High division, Thenar nerves.

Address for Correspondence: Dr. Kuldeep Suthar, 33, Mehsananagar Society, Near Avakar Service Station, Radhanpur Road, Mehsana-384002, Gujarat, India. Mobile - 9998846025

E-Mail: dr.kuldeepsuthar@yahoo.co.in

Access this Article online

Quick Response code

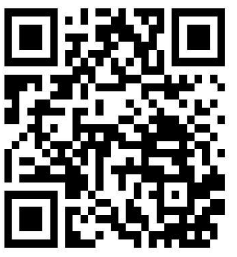

DOI: $10.16965 /$ ijar.2019.107

Journal Information

International Journal of Anatomy and Research

ICV for 2016 ISSN (E) 2321-4287 | ISSN (P) 2321-8967

90.30

https://www.ijmhr.org/ijar.htm

DOI-Prefix: https://dx.doi.org/10.16965/ijar

(cc) ET-Ne-SH

Article Information

Received: 09 Jan 2019

Peer Review: 09 Jan 2019

Revised: None
Accepted: 15 Feb 2019

Published (O): 05 Mar 2019

Published (P): 05 Mar 2019

\section{INTRODUCTION}

Variations are very common in body parts. Median nerve also has many anatomic variations. Knowledge regarding this is very important for clinical examinations and further surgical approaches of median nerve. The carpal tunnel, located on the palmar surface of the wrist, contains the median nerve, four tendons of the flexor digitorum superficialis, four tendons of the flexor digitorum profundus, and the tendon of the flexor pollicis longus. Since the nerve passes through the narrow carpal tunnel formed by the transverse carpal ligament [TCL] and the carpal bones and is crowded by the nine flexor tendons in the wrist joint area, many factors can cause increased pressure within the carpal tunnel, eventually compressing the nerve. It's therefore important for clinicians to recognize the frequency and multiplicity of the anomalous structures and variations within this region, especially the anatomical course of the median nerve and its branches [1].

Lanz classified these variations in four groups. 
$88.2 \%$ in thenar nerves, $7.3 \%$ in distal accessory branches, $2.8 \%$ high division and $1.7 \%$ proximal accessory branches [2].

High bifurcation (division) of the median nerve can be an isolated finding [3] or it can be associated with a persistent median artery [4] or an accessory muscle belly of the long finger flexor superficialis $[5,6,7]$.

Frequency of occurrence of observed variations of median nerve is extremely variable in published literature [8]. The purpose of this study was to understand the anatomical variations of median nerve in carpal tunnel particularly its divisions.

\section{MATERIALS AND METHODS}

This study is conducted in the Department of Anatomy, GMERS Medical College, DharpurPatan, Gujarat. Total 30 human cadavers were taken for the study. All 30 cadavers were fixed with formalin solution. The period of study was approximately 3 years. Age group was between 52-76 years including 18 males and 12 females. Skin incision was made according to Anatomy practical manual [9]. The transverse carpal ligament was opened by longitudinal incision in each cadaver in both the hands. The carpal tunnel and palms of the hands were inspected properly. The course of median nerve in carpal tunnel was inspected and photographed properly. Variations in the course [mainly divisions] of median nerve were properly observed for analysis.

\section{OBSERVATIONS AND RESULTS}

We have taken total 60 hands for examination. Among them, 30 [50\%] belong to right hand and 30 [50\%] belong to left hand. There were no any variations in 20 [33\%] hands. Divisions, branching and nerve distribution were according to standard anatomy textbooks. Variations were more in left hand compared to right and were approximately 23 [56\%] out of 40 [100\%]. Normally, median nerve is superficial structure in tunnel and passes between radial and ulnar bursae. But in one hand it was passing more nearer to ulnar and in another hand it was more nearer to radial bursae.

In one hand, three divisions of median nerve also found. It was in right hand. High division of median nerve dividing proximal to upper border of transverse carpal ligament [TCL] was found in total 6 [10\%] of all the hands. Among them, high division was more 4 in left hand compared to right hand in which, it was 2 .

In 4 hands, median nerve was dividing $4 \mathrm{~mm}$ above the proximal border of flexor retinaculum [FR] and in other 2 hands; it was dividing $8 \mathrm{~mm}$ above the proximal border of flexor retinaculum. It was unilateral in all the cadavers.

Here I am depicting some important figures. Figure 1. Showing normal division of median nerve into lateral and medial division and further lateral division gives off three proper digital branches and medial division gives off two common digital nerves. Figure 2. Showing normal division of median nerve just below flexor retinaculum. Figure 3 . Showing higher division of median nerve above the flexor retinaculum.

Fig. 1: Showing normal division of median nerve.

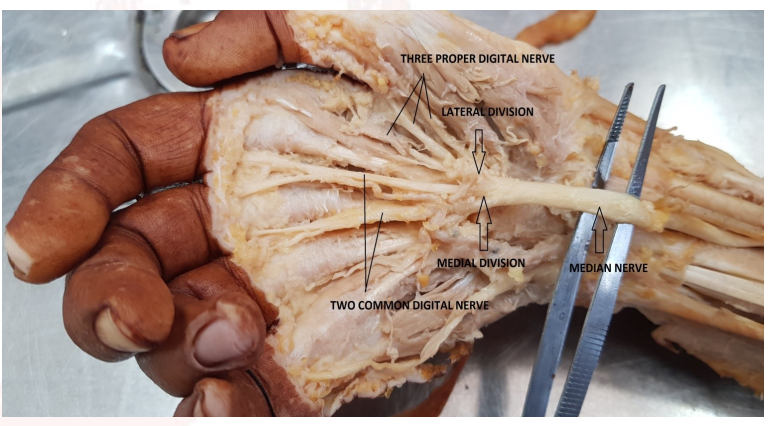

Fig. 2: Showing normal division [below flexor retinaculum] of median nerve.

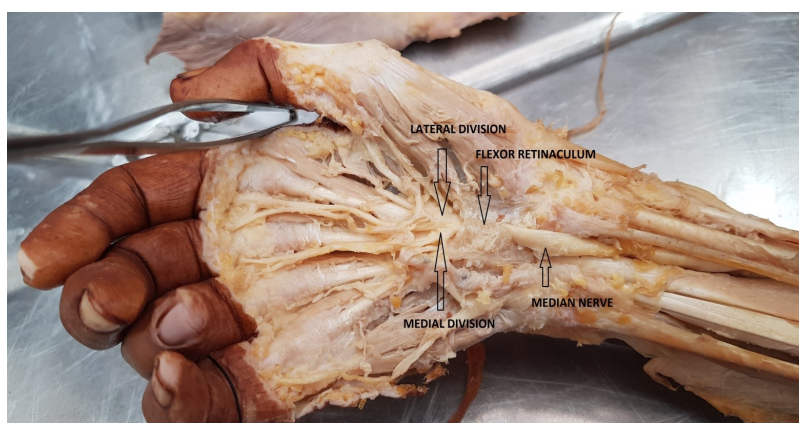

Fig. 3: Showing higher division [above flexor retinaculum] of median nerve.

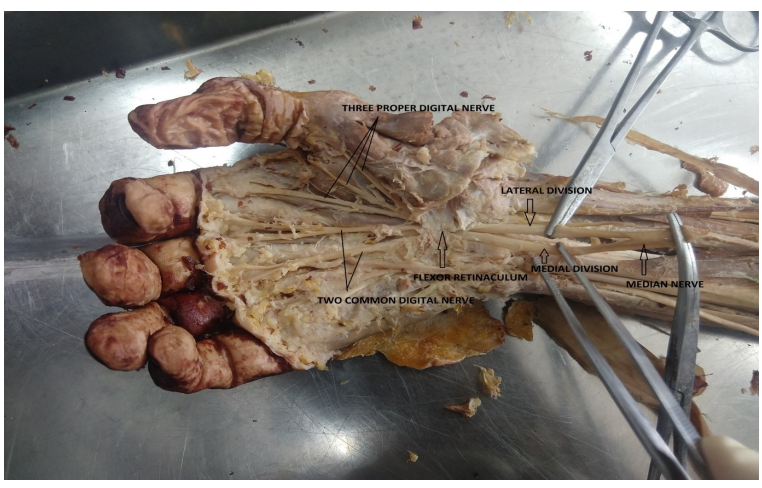




\section{DISCUSSION}

We found anatomical variations in 40 [66\%] hands out of 60 [100\%] hands in median nerve almost around $60 \%$. Variations were more in left hands. Rare variations of median nerve were not found in our study.

The incidence of variations in the anatomy of the median nerve is different in different studies and reports and also in different anatomical books. Difference is also found in cadaveric studies and clinical studies.

Bifurcation of the median nerve proximal to the transverse carpal ligament is a relatively common anatomical variation present in $1 \%$ to $3.3 \%$ of individuals undergoing carpal tunnel release surgery. High bifurcation of the median nerve can be an isolated finding or it can be associated with a persistent median artery or an accessory muscle belly of the long finger flexor superficialis [10].

In different 2 clinical studies, variations were more than $20 \%$ [11, 12]. In 4 cadaveric studies [Including our study], variations were more than $30 \%[1,13,14]$.

In a study by Lanz [2], he described high divisions of median nerve in 7 [2.9\%] of hands [Lanz type III]. It was 8\% in Kuntal Vashistha [8] study, $5 \%$ in E. Mizia et al. [1] study.

In our study, it is in 6 hands which are $10 \%$ of all the hands which is more than R Mitchell [10] study and nearer to Kuntal Vashistha [8] study.

\section{CONCLUSION}

Carpal tunnel surgery or release is very common in hand due to median nerve entrapment in carpal tunnel. Knowledge regarding variations and divisions is very important for hand surgeon and plastic surgeon for surgical decompression of median nerve.

\section{Conflicts of Interests: None}

\section{REFERENCES}

[1]. E. Mizia, W. Klimek-Piotrowska, J. Walocha, R. Rutowski, R. Wojtala. The median nerve in the carpal tunnel. Folia Morphol. 2011; 70 (1): 41-46.

[2]. Lanz $u$. Anatomical variations of the median nerve in the carpal tunnel. J Hand Surge (AM). 1977; 22: 44-53.

[3]. Szabo RM, Pettey J. Bilateral median nerve bifurcation with an accessory compartment within the carpal tunnel. J Hand Surg. 1994; 19B: 1744-1746.

[4]. Jeon IH, Kim PT, Park IH, Park BC, Ihn JC. High bifurcation of median nerve at the wrist causing common digital nerve injury in endoscopic carpal tunnel release. J Hand Surg. 2002; 27B: 580-582.

[5]. Lindley SG, Jackson MS, Kleinert JM. Prevalence of anatomic variations encountered in elective tunnel release. J Hand Surg. 2003; 28A: 849-855.

[6]. Gutowski KA, Oliver WA, Mehrara BJ, Friedman DW. Arteriovenous malformation of a persistent median artery with a bifurcated median nerve. Plast Reconstr Surg. 2000; 106:1336-1339.

[7]. Fernandez-Garcia S, Pi-Folguera J, Estallo-Matono F. Bifid median nerve compression due to a musculotendinous anomaly of FDS to the middle finger. J Hand Surg. 1994; 19B: 616-617.

[8]. Kuntal Vashistha. J. Anat. Soc. India 2011; 60 (2): 193-198.

[9]. Romanes GJ. Manual of practical Anatomy in forearm and hand. $15^{\text {th }}$ edn, Oxford: Oxford university press. 1986; 1: 73-81.

[10]. R mitchell, a Chesney, S Seal, I mcKnight, a Thoma. Anatomical variations of the carpal tunnel structures. Can J plast Surg. 2009; 17(3): e3-e7.

[11]. Ahn DS, Yoon ES, Koo SH, Park SH. A prospective study of the anatomic variations of the median nerve in the carpal tunnel in Asians. Ann Plast Surg. 2000; 44: 282-287.

[12]. Hurwitz PJ. Variation in the course of the thenar motor branch of the median nerve. J Hand Surg. 1996; 21B: 344-346.

[13]. Barbe M, Bradfield J, Donathan M, Elmaleh J. Coexistence of multiple anomalies in the carpal tunnel. Clin Anat. 2005; 18 (4): 251-259.

[14]. Tountas CP, Bhrle DM, MacDonald CJ, Bergman RA. Variations of the median nerve in the carpal. J Hand Surg. 1987; 12: 708-712.
How to cite this article:
Pankaj B Maheria, Kuldeep N Suthar. STUDY OF ANATOMICAL VARIATIONS (DIVISION) OF MEDIAN NERVE IN CARPAL TUNNEL IN NORTH GUJARAT. Int J Anat Res 2019;7(1.3):6311-6313. DOI: 10.16965/ijar.2019.107 